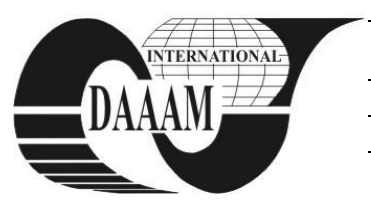

Annals of DAAAM for 2012 \& Proceedings of the 23rd International DAAAM Symposium, Volume 23, No.1, ISSN 2304-1382 ISBN 978-3-901509-91-9, CDROM version, Ed. B. Katalinic, Published by DAAAM International, Vienna, Austria, EU, 2012 Make Harmony between Technology and Nature, and Your Mind will Fly Free as a Bird

\title{
COMPUTER AIDED SOLUTION IN AN APPLIED ELASTICITY EDUCATIONAL CASE STUDY - STATICALLY INDETERMINATE SYSTEM OF BARS
}

\author{
OANTA, E[mil]; PANAIT, C[ornel]; BARHALESCU, M[ihaela] L[uminita]; \\ SABAU, A[drian] \& AXINTE, T[iberiu]
}

\begin{abstract}
Most of the real structures are statically indeterminate and they cannot be analytically computed by simply applying the equilibrium conditions. This is why students must possess the appropriate knowledge to approach this type of problems, a first solution being based on analytic methods.

The paper presents a case-study regarding the use of the MohrMaxwell method to conceive a solution which, once implemented, it can be used to solve a series of educational models. The original software application has many parameters and it can be easily used by the professor in order to solve the indeterminancy for other structures which have a similar or simpler shape. Moreover, using the specific attributes of the symmetrical and anti-symmetrical structuresand applying the superposition principle, several other problems may be solved. The original software was developed in MINGW using ECLIPSE and it consists of 1100 computer code lines for the basic modules and for the case studies solved, until now.

Keywords:Statically-indeterminate-system, computer-basedsolution, applied elasticity, educational applications, original software
\end{abstract}

\section{INTRODUCTION}

Most of the real structures are statically indeterminate and they cannot be analytically computed by simply applying the equilibrium conditions. The statically indeterminate systems of bars may be either exterior indeterminate or interior indeterminate and they are defined as structures whose number of unknowns is larger than the number of equilibrium conditions for that given problem (3 for plane problems and 6 for spatial problems).

There are several analytical methods to solve this kind of problems, [1], such as:

- direct methods;

- strain energy methods;

- virtual displacement method;

- special methods (method of initial parameters, three moments equation aka Clapeyron's Theorem, moment distribution method, etc).

Students must possess the necessary knowledge to approach this type of problems. Beside the general topics of the curricula, strength of materials must offer the theoretical background, the real structures whose technical solutions must be evaluated, and most important nowadays, severalcase-studies to be solved by the students. The most effective solving methods conceived by the professors are the computer based solutions, [7], [8].
Until now computer based original solutions in structural mechanics were used mostly in design and research. This method can be successfully applied in education if it is consistently employed as a strategic option in the development of computer based instruments.

\section{THEORETICAL BACKGROUND}

Solving the statically indeterminate systems of bars starts with the calculus of the unknowns, notion also known as degree of redundancy or statical indeterminancy. Primary unknowns are the forces and moments corresponding to the redundant constraints, as well as the internal forces and moments which can be also considered. Thissolving method is designated as 'the force method' because the unknows are forces and moments known as primary unknowns. The statically determinate system resulted from the initial statical indeterminate system without the primary unknowns is designated 'primary system'. It is important to conceive a primary system which offers a facile solution, without complicated calculi.

Let us consider the general case of a statically indeterminate system with 'n' unknownsdenoted $X_{i}$. The general form of the accordingly system of canonical equations is:

$$
\left[\begin{array}{cccccc}
\delta_{11} & \delta_{12} & \cdots & \delta_{1 j} & \cdots & \delta_{1 n} \\
\delta_{21} & \delta_{22} & \cdots & \delta_{2 j} & \cdots & \delta_{2 n} \\
\vdots & \vdots & \ddots & \vdots & \cdot & \vdots \\
\delta_{i 1} & \delta_{i 2} & \cdots & \delta_{i j} & \cdots & \delta_{i n} \\
\vdots & \vdots & \cdot & \vdots & \ddots & \vdots \\
\delta_{n 1} & \delta_{n 2} & \cdots & \delta_{n j} & \cdots & \delta_{n n}
\end{array}\right] \cdot\left[\begin{array}{c}
X_{1} \\
X_{2} \\
\vdots \\
X_{j} \\
\vdots \\
X_{n}
\end{array}\right]+\left[\begin{array}{c}
\Delta_{10} \\
\Delta_{20} \\
\vdots \\
\Delta_{j 0} \\
\vdots \\
\Delta_{n 0}
\end{array}\right]=0
$$

Coefficients $\delta_{i j}$ of the canonical equations have the physical meaning of displacements of the primary structure produced by the unit primary unknowns. The $\delta_{i j}$ unit displacement is oriented along the direction of the $X_{i}$ unknown and it is generated by the $X_{j}$ unit unknown.The according real displacement along the $X_{i}$ unknown, generated by the $X_{j}$ real unknown is

$$
\Delta_{i j}=\delta_{i j} \cdot X_{j}
$$


The $\Delta_{j 0}$ free term have the physical significance of displacement along the $X_{j}$ unknown, produced by the according loads in the primary system.

The general form of the displacement along the $X_{i}$ unknown is:

$\Delta_{i}=\delta_{i 1} \cdot X_{1}+\cdots+\delta_{i j} \cdot X_{j}+\cdots+\delta_{i n} \cdot X_{n}+\Delta_{i 0}$,

which, taking into account (2), it results

$$
\Delta_{i}=\Delta_{i 1}+\cdots+\Delta_{i j}+\cdots+\Delta_{i n}+\Delta_{i 0},
$$

or, in a concise form

$$
\Delta_{i}=\sum_{j=0}^{n} \Delta_{i j}
$$

This means that the $\Delta_{i}$ displacement along the $X_{i}$ unknown is the sum of the displacement produced by all the loads and reactions applied on the structure.

But this displacement is along an unknown $X_{i}$, which is a reaction acting in a support of the structure, the according displacements being constrained, it means that

$$
\Delta_{i}=0
$$

Coming back to the $\delta_{i j}$ unit displacement, one can notice that, because of the reciprocal displacement theorem, we have

$$
\delta_{i j}=\delta_{j i} \text {,for } i \neq j
$$

We remind that the $\delta_{i i}$ coefficients located on the principal diagonal of (1) are designated principal (unit) displacements, while the other coefficients, these are $\delta_{i j}$ for $i \neq j$ are denominated secondary unit displacements.

We denote by $M_{Y 0}$ the free body diagram of the bending moment, for the primary system. We also denote by $m_{Y j}$ the bending moment diagrams for the primary structure, without the external (initial) loads and loaded only by the unit force/moment corresponding to the $X_{j}=1$ unknown.

Taking into account only the bending moment with respect to the $Y$ axis, the according unit displacementsare computed using the relations:

$$
\begin{gathered}
\delta_{i j}=\sum_{k=1}^{N I}\left\{\int_{0}^{L_{k}}\left[\frac{m_{Y i}(x) \cdot m_{Y j}(x)}{E \cdot I_{Y}}\right] d x\right\} \\
\delta_{i i}=\sum_{k=1}^{N I}\left\{\int_{0}^{L_{k}}\left[\frac{m_{Y j}^{2}(x)}{E \cdot I_{Y}}\right] d x\right\} \\
\Delta_{i 0}=\sum_{k=1}^{N I}\left\{\int_{0}^{L_{k}}\left[\frac{m_{Y i}(x) \cdot M_{Y 0}(x)}{E \cdot I_{Y}}\right] d x\right\}
\end{gathered}
$$

where $k$ is the identifier of the current interval of the structure and $N I$ is the total number of intervals. For curved intervals $d x \rightarrow d s=R \cdot d \varphi$ and $L_{k} \rightarrow \varphi_{\max k}$.

One can notice that $\delta_{i i}>0$, while the other coefficients may be positive, negative or zero.

Once the $\delta_{i j}$ and $\Delta_{j 0}$ coefficients are computed, there must be solved the system of equations (1), the results being the $X_{j}, j=1, n$ unknowns.

The final stage is to draw the free body diagrams and to compute the deflections.

\section{CASE STUDY}

As mentioned before, it is very important to conceive an effective primary system which minimizes the overall volume of calculi.One of the aspects to be considered is the possible symmetry or antisymmetry of the problem.

These aspects are also important in designing the computer based solutions. It is far more important to design computer based analytic models because the complex research problems can be solved only using the computer as main instrument of investigation and for the data gathering, mining and refinement.

Let us consider the system of bars in figure 1 which is a half of the structure to be considered. The whole structure may be either anti-symmetrical (figure 2), or symmetrical(figure 3) with respect to section 4 where is an internal pinned connection.

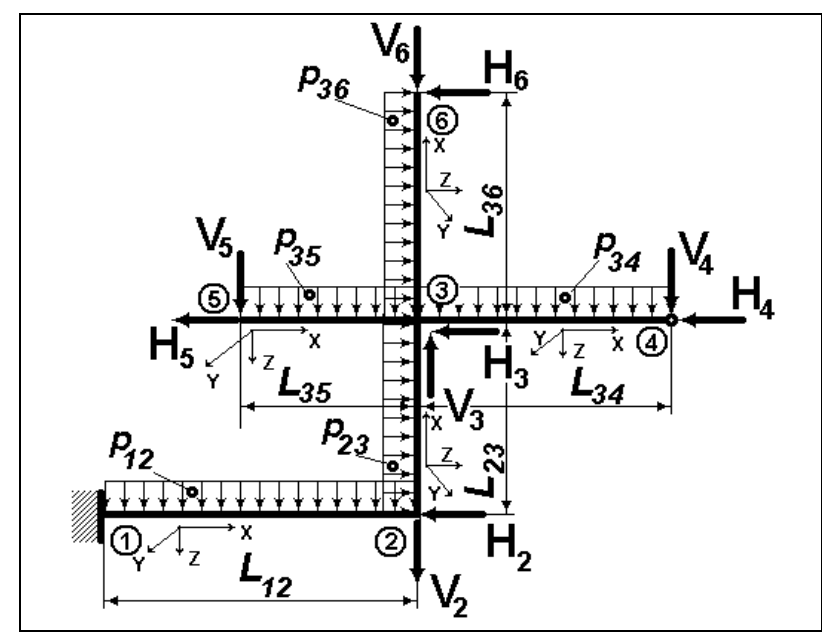

Fig. 1. Model of a half of the structure

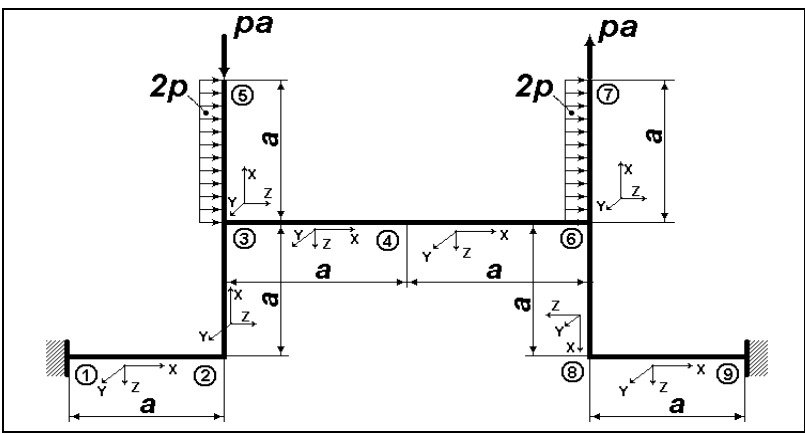

Fig. 2. Anti-symmetrical problem which can be solved using the original application 


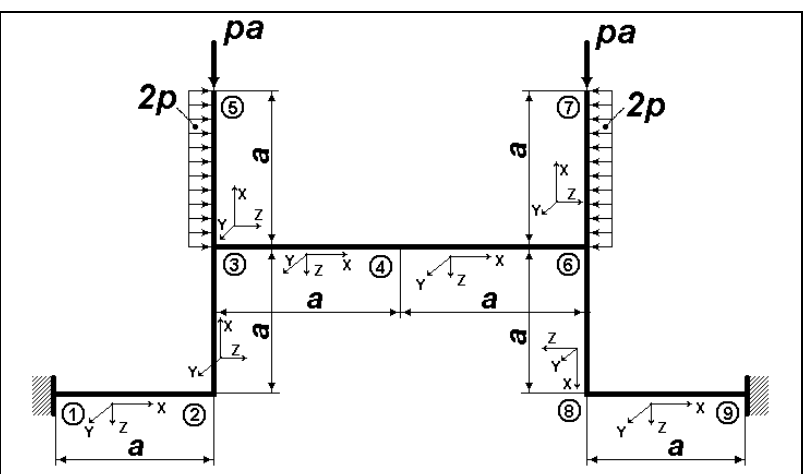

Fig. 3. Symmetrical problem which can be solved using the original application

The first stage to solve the problem is to apply the appropriate boundary conditions regarding the symmetry or anti-symmetry of the structure in order to have the simplest primary system, in this case a half of the structure (fig 1). We remind that for a symmetrical structure $T_{Z 4}=0$ and the unknowns are $X_{1}=N_{4}$ and $X_{2}=M_{Y 4}$, while for an anti-symmetrical structure $N_{4}=0$ and $M_{Y 4}=0$ and the unknown is $X_{1}=T_{Z 4}$ .If in section 4 we have an internal pinned connection, it can be considered that $X_{2}=M_{Y 4}=0$.

The next stage is to compute the coefficients (6), (7) and (8), belonging to the system of canonical equations (1), for which several integrals must be computed. The function under the integral is the product between the laws of variation of some bending moments on the current interval. The integrals can be computed either directly, or using graphical techniques, like Veresciaghin. In order to have a computing instrument which can be used in several other cases, it was conceived a computeraided method to perform the calculi. variation of the bending moments must be automatically generated. Next is an example of the laws of variation on interval $4 \rightarrow 3$, the sign rule being $\frac{+ \text { Internal Force }}{+ \text { Axis }}, x \in\left(0, L_{34}\right)$,

$$
\left\{\begin{array}{c}
N_{43}(x)=-H_{4} \\
T_{Z 43}(x)=V_{4}+p_{34} \cdot x \\
M_{Y 43}(x)=-V_{4} \cdot x-\frac{p_{34} \cdot x^{2}}{2}
\end{array}\right.
$$

The intervals are swept starting from the free end and going to section 3 where the effects must be added, so it is used the following relation for the summation of the internal forces, moments and loads:

$$
\left\{\begin{aligned}
N_{32}^{3} & =-T_{Z 43}^{3}+T_{Z 53}^{3}+N_{63}^{3}-V_{3} \\
T_{Z 32}^{3} & =N_{43}^{3}-N_{53}^{3}+T_{Z 63}^{3}-H_{3} \\
M_{Y 32}^{3} & =M_{Y 43}^{3}-M_{Y 53}^{3}+M_{Y 63}^{3}
\end{aligned}\right.
$$

The resulted internal forces are employed for the calculi on the $3 \rightarrow 2$ and $2 \rightarrow 1$ intervals.

\section{COMPUTER AIDED SOLUTION}

Figure 4 presents the original computer code developed in $\mathrm{C}++$, using the Eclipse environment. The software consist of more than 1100 computer code lines and it includes: data structures definitions, modules employed to initialize the data, compute the internal forces and moment, automatic data generation for a given case

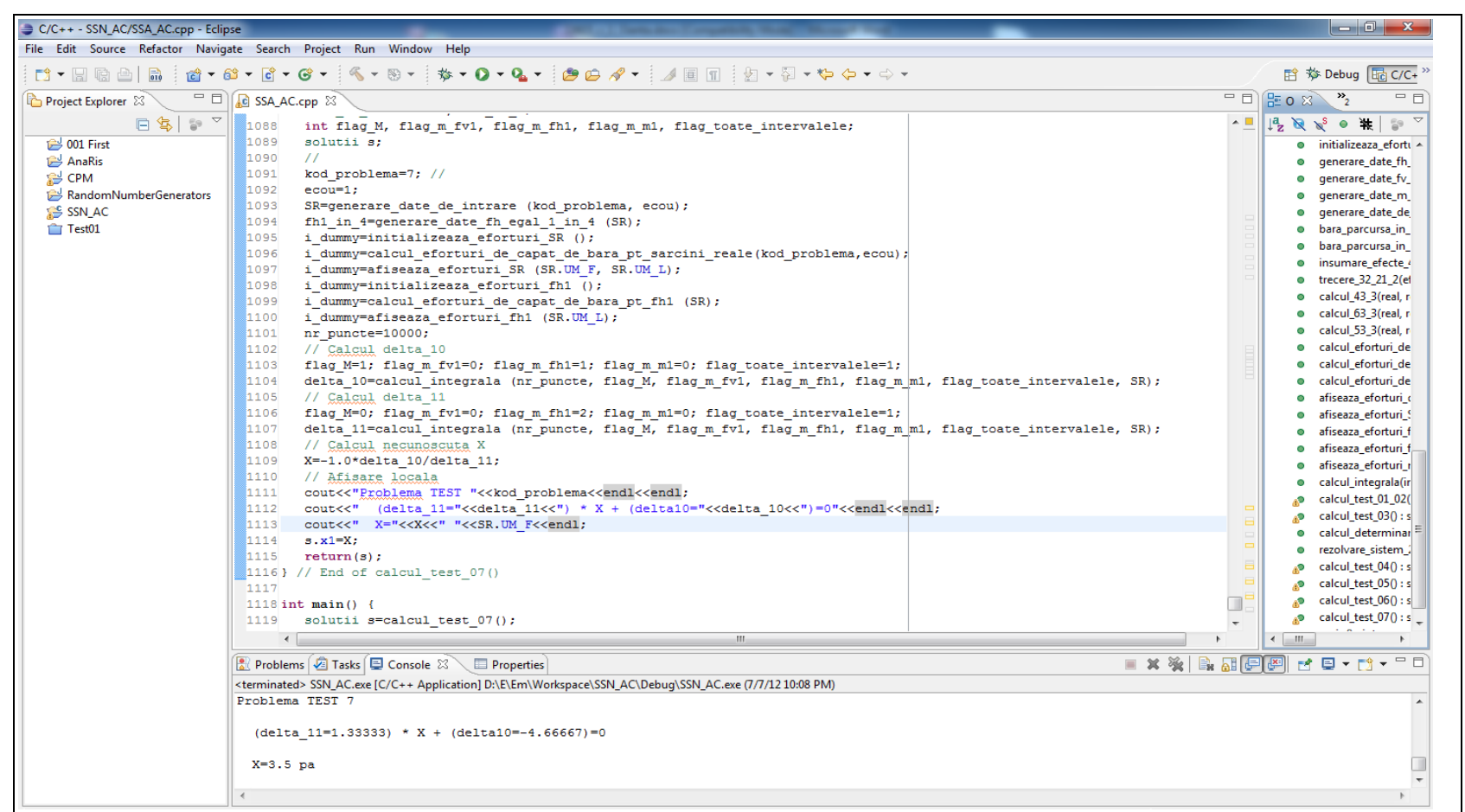

Fig. 4. Screenshot of the original software in Eclipse 
study, calculus of the coefficients of the system of canonical equations, solution of the system of canonical equations, presentation of the computed data and of the output data which has technical relevancy.

As it can be noticed, the structure of the software application is flexible, the user being allowed to develop a small program module (function) which solves a new loadcase, the template of the technical problem being presented in figure 1 .

\section{CONCLUSION}

Statically Indeterminate Systems may be solved using several methods; among them we can notice that Computer Aided original solutions are important instruments in the development of the computer-based models in structural mechanics, [3], [4].

Regarding the limitations of the study, one can notice that the original software is based on 'the force method' as a unique theoretical background, being planned the use of other methods at a later stage. Another limitation is about the specific structure considered, the software being particular from this point of view. However,from the educational point of view,[6], the original software presented in the previous sections was employed to automatically solve the indeterminancy of 34 problems and it can be used as a problem automatic solver for many other case studies.

From the methodological point of view, using this software, students can fill the gap between different topics of their curricula, such as: computer programming, computer aided design, strength of materials and others.

The study may be also considered as a pilot project in the computer based original solutions of the statically indeterminate systems of bars. This analytic study may be used at a later stage together with numerical and experimental studies in order to develop hybrid models, which are modern instruments of research.

This computer-based method to acquire knowledge is a long run concern of the authors which was extensively used in order to develop models required in research, design and education, [2], [5].From this standpoint, the software presented in the paper is included in a strategy which aims the development of advanced instruments for research.

\section{ACKNOWLEDGEMENTS}

Several of the ideas presented in the paper are the result of the models developed in the framework of the scientific research study 'Development of computer assisted marine structures', Emil Oanta, Cornel Panait, Ghiorghe Batrinca, Alexandru Pescaru, Alexandra Nita, Feiza Memet, which is a component of the RoNoMar project, 2010, sponsor of this paper.

Ideas regarding the computer based instruments in applied elasticity are the result of the models developed in the framework of the MIEC2010 bilateral Ro-Md research project, Oanta, E., Panait, C., Lepadatu, L., Tamas, R., Constantinescu, M., Odagescu, I., Tamas, I., Batrinca, G., Nistor, C., Marina, V., Iliadi, G., Sontea, V., Marina, V., Balan, V. (2010-2012), "Mathematical Models for Inter-Domain Approaches with Applications in Engineering and Economy", MIEC2010 - Bilateral Romania-Moldavia Scientific Research Project, under the supervision of the National Authority for Scientific Research (ANCS), Romania, that is the follow-up of the ID1223 scientific research project: Oanta, E., Panait, C., Nicolescu, B., Dinu, S., Pescaru, A., Nita, A., Gavrila, G., (2007-2010), "Computer Aided Advanced Studies in Applied Elasticity from an Interdisciplinary Perspective", under the supervision of the National University Research Council (CNCSIS), Romania.

\section{REFERENCES}

[1] Karnovsky, I. A.; Lebed, O (2010), Advanced Methods of Structural Analysis, Springer Publishing House, ISBN 978-14419-1046-2, e-ISBN 978-1-4419-1047-9. DOI 10.1007/978-14419-1047-9, Springer Science+Business Media, LLC 2010

[2] Oanta, E.; Barhalescu, M. \& Sabau, A., (2011). Management of Change Based on Creative Inter-Domain Syntheses, Proceedings of the $7^{\text {th }}$ International Conference on Management of Technological Changes, September $1^{\text {st }}-3^{\text {rd }}$, 2011, Alexandroupolis, Greece, Vol II, ISBN (Vol. II) 978-960-994863-0, ISBN 978-960-99486-1-6, Costache Rusu (Ed.), pp. 589-592, Democritus University of Thrace, Alexandroupolis, Greece, 2011

[3] Oanta, E.; Panait, C.; Batrinca, G. \& Pescaru, A., (2011). Basic Concepts to Design the Software Application of a Computer Based Mechanical Engineering Model, Annals of DAAAM for 2011 \& Proceedings of the $22^{\text {nd }}$ International DAAAM Symposium, ISBN 978-3-901509-83-4, ISSN 1726-9679, pp 0505-0506, Branko Katalinic (Ed.), Published by DAAAM International, Vienna, Austria 2011

[4] Oanta, E.; Panait, C.; Batrinca, G. \& Pescaru, A., (2011). Computer Based Educational Model of the Bent Hull in the Context of the Maritime Education, Annals of DAAAM for 2011 \& Proceedings of the $22^{\text {nd }}$ International DAAAM Symposium, ISBN 978-3-901509-83-4, ISSN 1726-9679, pp 0503-0504, Branko Katalinic (Ed.), Published by DAAAM International, Vienna, Austria 2011

[5] Oanta, E.; Panait, C.; Marina, V.; Marina, V.; Lepadatu, L.; Constantinescu, E.; Barhalescu, M. L.; Sabau, A. \& Dumitrache, C. L., (2011). Mathematical Composite Models, a Path to Solve Research Complex Problems, Annals of DAAAM for 2011 \& Proceedings of the $22^{\text {nd }}$ International DAAAM Symposium, ISBN 978-3-901509-83-4, ISSN 1726-9679, pp 0501-0502, Branko Katalinic (Ed.), Published by DAAAM International, Vienna, Austria 2011

[6] Oanta, E. (2012); Solved problems of Strength of Materials with Applications in Marine Engineering - Examples of examination subjects, Nautica Publishing House, ISBN 978-606-8105-65-9, Constanta Romania

[7] Sabau, A.; Oanta, E. \& Barhalescu, M., (2011). Impact Of The Use Of The Modern Methods In The Training Of Marine Engineer Cadets,Proceedings of the $7^{\text {th }}$ International Conference on Management of Technological Changes, September $1^{\text {st }}-3^{\text {rd }}$, 2011, Alexandroupolis, Greece, Vol II, ISBN (Vol. II) 978-96099486-3-0, ISBN 978-960-99486-1-6, Costache Rusu (Ed.), pp. 421-424, Democritus University of Thrace, Alexandroupolis, Greece, 2011

[8] Sabau, A.; Barhalescu, M. \& Oanta, E., (2011). Simulation Programs in Teaching Activity, Proceedings of the $7^{\text {th }}$ International Conference on Management of Technological Changes, September $1^{\text {st }}-3^{\text {rd }}$, 2011, Alexandroupolis, Greece, Vol II, ISBN (Vol. II) 978-960-99486-3-0, ISBN 978-960-99486-1-6, Costache Rusu (Ed.), pp. 425-428, Democritus University of Thrace, Alexandroupolis, Greece, 2011 